\title{
Effect of four weeks' high dose ipratropium bromide treatment on lung mucociliary clearance
}

\author{
RG TAYLOR, D PAVIA, JE AGNEW, MT LOPEZ-VIDRIERO, SP NEWMAN, \\ T LENNARD-JONES, SW CLARKE
}

From the Departments of Thoracic Medicine and Medical Physics, Royal Free Hospital and School of Medicine, London

ABSTRACT In a randomised, double blind crossover study the effect of high dose ipratropium bromide ( $200 \mu \mathrm{g}$ three times daily given by metered dose inhaler for four weeks) on lung mucociliary clearance and on the wet weight and mean apparent viscosity of sputum was compared with that of placebo. Six smokers, six ex-smokers, and three non-smokers (12 men and three women, median age 60 years) were studied. Eight subjects had chronic obstructive lung disease (median FEV $46 \%$ predicted) and seven had asthma (FEV $70 \%$ predicted). Seven subjects produced sputum regularly, two of whom had asthma. Clearance of secretions was measured by an inhaled radioaerosol technique. The number of coughs and the wet weight, radioactive content, and mean apparent viscosity of sputum produced during the six hour observation period were recorded, as was the mean wet weight of sputum produced during the last two 24 hour periods ending each treatment. Comparison with placebo showed that treatment with high dose ipratropium bromide was associated with a significant increase in the penetration index of inhaled particles, but there was no significant change in alveolar deposition of particles or in tracheobronchial clearance, uncorrected or corrected for sputum expectorated. The wet weight of sputum produced, its radioactive content, and mean apparent viscosity were similar after treatment with ipratropium bromide and placebo. These results show that high dose inhaled treatment with the synthetic anticholinergic bronchodilator ipratropium bromide for four weeks is not associated with detectable modification of the clearance of secretions from the lungs, or of sputum volume or viscosity.

The synthetic anticholinergic drug ipratropium bromide is an effective bronchodilator when given by metered dose inhaler $40 \mu \mathrm{g}$ (that is, two puffs) four times daily, and this dosage for a week does not alter the clearance of secretions from the lungs. ${ }^{12}$ Reports of the effects of higher doses of ipratropium bromide come from studies in which only single doses were given. Doses of up to $400 \mu \mathrm{g}$ caused greater and longer lasting bronchodilatation, ${ }^{3-8}$ while doses of up to $200 \mu \mathrm{g}$ did not affect lung mucociliary clearance. ${ }^{5} 9$

Bearing in mind the effect of atropine on secretions and lung clearance, ${ }^{10}$ we have looked more closely for any deleterious effect of treatment with ipratropium bromide inhaled in high doses. We report here the effects on sputum production and apparent viscosity

Address for reprint requests: Dr RG Taylor, Department of Thoracic Medicine, Royal Free Hospital, London NW3 2QG.

Accepted 17 September 1985 and on lung mucociliary clearance of four weeks' treatment with ipratropium bromide $200 \mu \mathrm{g}$ three times daily given by metered dose inhaler to patients with airflow obstruction.

Table 1 Details of the patients and their usual medication

\begin{tabular}{lc}
\hline Male:female & $12: 3$ \\
Age: median (range) (y) & $60(27-71)$ \\
Smoking habit (n) & 6 \\
Smoker & 6 \\
Ex-smoker & 3 \\
Non-smoker & 8 \\
Diagnosis & $46(24-70)$ \\
Chronic obstructive lung disease (n) & 7 \\
$\quad$ Median (range) (\% predicted FEV & ) \\
Asthma (n) & $70(29-91)$ \\
$\quad$ Median (range) (\% predicted FEV & \\
Medication: number normally taking: & 13 \\
Inhaled $\beta_{2}$ adrenoceptor agonist & 4 \\
Oral and inhaled $\beta_{2}$ adrenoceptor agonist & 9 \\
Inhaled corticosteroid & 3 \\
Oral and inhaled corticosteroid & 2 \\
Inhaled ipratropium bromide (standard dose) & 1 \\
Inhaled sodium cromoglycate & 7 \\
Oral aminophylline & \\
\hline
\end{tabular}




\section{Methods}

\section{SUBJECTS}

Twenty three patients were recruited to the study, but eight of them failed to complete it. The physical characteristics and usual medication of the 15 patients who completed the study are given in table 1. An ex-smoker was defined as one who had not smoked for at least a year, and a non-smoker as one who had never smoked. All the subjects had airflow obstruction. Those who had reversibility of their obstruction amounting to $20 \%$ or more with conventional bronchodilator treatment were diagnosed as having asthma; smokers or ex-smokers with less reversibility were diagnosed as having chronic obstructive lung disease.

The study was approved by the hospital's ethical committee, and all the subjects gave their written consent to be studied.

\section{LUNG FUNCTION}

Peak expiratory flow (PEF) was measured with a Wright meter, and $\mathrm{FEV}_{1}$, forced vital capacity (FVC), and forced mid expiratory flow $\left(\mathrm{FEF}_{25-75}\right)$ with a Vitalograph spirometer. Maximal expiratory flow at $50 \%\left(\dot{\mathrm{V}} \max _{50}\right)$ and $25 \%\left(\dot{\mathrm{V} m a x}{ }_{25}\right)$ of vital capacity were measured with an Ohio 840 spirometer and Bryans $26000 x-y$ recorder. The largest of three recordings of $\mathrm{PEF}, \mathrm{FEV}_{1}, \mathrm{FVC}$, and $\mathrm{FEF}_{25-75}$ and the value of $\operatorname{Vmax}_{50}$ and $\operatorname{Vmax}_{25}$ from the largest of three vital capacity tracings were each expressed as a percentage of the predicted value. ${ }^{1112}$

\section{LUNG MUCOCILIARY CLEARANCE}

The method of measurement of lung mucociliary clearance has been fully described. ${ }^{12}$ Five micron polystyrene particles were tagged firmly with technetium $99 \mathrm{~m}\left({ }^{99 \mathrm{~m}} \mathrm{Tc}\right)^{13}$ and inhaled under strictly controlled conditions. The clearance of the particles from the lungs was monitored by collimated scintillation counters placed anteriorly and posteriorly to the chest. Thirty second counts were taken immediately after and at half hour intervals for six hours after inhalation of the radioaerosol. Alveolar deposition was determined as the percentage of the initial lung burden remaining in the lungs at 24 hours. ${ }^{14}$ The results were expressed as whole lung clearance, and as tracheobronchial clearance (whole lung clearance minus alveolar deposition) uncorrected and corrected for cough productive of sputum containing radioactivity. ${ }^{15}$

The initial topographical distribution of the radioaerosol deposited in the lungs was monitored with a gamma camera (International General Electric) with a large field of view interfaced with a computer (Node- crest). Posterior views were obtained to derive a pene tration index for the ${ }^{99 \mathrm{~m}} \mathrm{Tc}$ labelled particles (ratio of: counts recorded over peripheral lung to thoses recorded over central lung). ${ }^{16}$ This index estimates thes degree of penetration into the lungs of this radio $\frac{}{-}$ aerosol relative to that of labelled krypton gas, ${ }^{81 \mathrm{~m}} \mathrm{Kr}$ that was subsequently inhaled.

STUDY PROTOCOL

The study was conducted in a double blind, crossove $\vec{P}$ fashion. After baseline measurement of lung mu $=$ cociliary clearance, the patients were allocated rano domly to receive either ipratropium bromide - tw puffs three times daily ( $100 \mu \mathrm{g}$ per puff) —or a placebo that was identical in composition except for active drug - two puffs three times daily-for four week $\stackrel{+}{\text { f }}$ from identical metered dose inhalers. They were in 6 structed to inhale in the recommended manner. ${ }^{1}$ ? Randomisation was arranged so that half the patients should receive ipratropium bromide first; in fact, six received the active drug and nine placebo. The sub을 jects continued to use the test inhalers for four weeks. and while their mucociliary clearance was being mea sured after inhaling radioaerosol, but they stopped taking aminophylline and oral and inhaled $\beta_{2}$ adre응 noceptor agonist drugs during these six hours and for at least 12 hours beforehand, to avoid any influence on mucociliary function. ${ }^{18}$ Otherwise, since this studfo was not designed to assess the bronchodilator effect of high dose ipratropium bromide, the patient continued to take their regular treatment throughou $\mathrm{B}$ the study, recording the number of puffs taken daily from their usual $\beta_{2}$ agonist inhaler during each foup week treatment period. While having each treatment the subjects also recorded on diary cards their daile assessment of breathlessness, cough, wheeze, and sat $\tilde{x}$ isfactory sleep according to a four point scale. Smok $\frac{\sigma}{-}$ ing was not permitted for at least one hour before of during the six hour observation period. During this period the number of coughs was counted and an expectorated sputum collected, its wet weight an\& radioactive content were recorded, and its mean apparent viscosity was measured with a modified cap을 illary viscometer (Moleculex). We also recorded the wet weight of sputum produced at the end of each treatment period and during the 24 hours immediatel $\hat{S}_{0}^{\circ}$ before and the 24 hours after inhalation of radio aerosol. The 24 hour sputum wet weight was taken as the mean of these two observations.

The subjects performed lung function tests at thळ end of each four week treatment period, immediatelis? before they inhaled the radioaerosol for measuremento of lung mucociliary clearance, and about two hour? after inhaling the last dose of test medication.

All adverse effects occurring during the course of the study were noted. 
Table 2 Results of lung function tests (as percentage of predicted, means with standard errors in parentheses) at the beginning of the study, and after four weeks' treatment with placebo and ipratropium bromide

\begin{tabular}{llllll}
\hline & FEV & FVC & PEF & $V_{\max _{30}}$ & $V \max _{25}$ \\
\hline Baseline & $53.1(5.4)$ & $77.4(5.3)$ & $54.3(6.0)$ & $12.0(2.5)$ & $18.3(4.5)$ \\
Placebo & $55.6(5.1)$ & $80.7(4.9)$ & $57.7(7.0)$ & $12.9(2.8)$ & $19.1(4.7)$ \\
Ipratropium bromide & $60.6(6.3)$ & $84.9(5.0)$ & $60.3(6.7)$ & $12.1(1.7)$ & $19.9(4.2)$ \\
\hline
\end{tabular}

FVC - forced vital capacity; PEF-peak expiratory flow; $\hat{V}_{\max }$ and $\hat{V} \max _{25}$-maximal expiratory flow at $50 \%$ and $25 \%$ of vital capacity.

The data were initially analysed by means of Friedman's two way analysis of variance. ${ }^{19}$ Where this showed significant differences between groups, the results were analysed further with Wilcoxon's signed rank test for matched pairs. ${ }^{19}$ Analysis of the results of the lung function tests (apart from PEF) was based on the results from 14 patients, because one patient was breathless at one visit and did not complete the tests. The penetration index was not determined in two subjects because of technical failure.

\section{Results}

The results of lung function tests are shown in table 2 . Treatment with ipratropium bromide was associated with a significant $(p<0.01)$ increase in forced vital capacity, but there was no significant change in measures of expiratory flow.

Table 3 shows the values for mean inspiratory flow, penetration index, and alveolar deposition of radioaerosol. The penetration index was higher after treatment with ipratropium bromide than with placebo $(p=0.01)$ and higher after placebo treatment than at baseline $(p<0.01)$, although alveolar deposition and mean inspiratory flow did not change significantly.

Comparison of the results obtained after treatment with placebo and with ipratropium bromide showed no significant difference in the amount of radioaerosol remaining in the lungs at any half hour interval up to six hours. No significant difference was detected whether the results were expressed as whole lung clearance or as tracheobronchial clearance uncorrected (figure) or corrected for productive cough, and no significant difference was evident when analysis was confined to the seven subjects who regularly produced sputum. In these seven subjects, two of whom were asthmatic, the number of coughs and the wet weight and mean apparent viscosity of sputum produced during the six hour observation period were all the same after ipratropium bromide as after placebo, as was the wet weight of sputum collected during 24 hours at the end of each treatment period (table 4).

There was no significant difference between the baseline results and those obtained after use of the placebo inhaler for four weeks in respect of uncorrected (figure) or corrected tracheobronchial clearance, sputum wet weight, or mean apparent viscosity (table 4).

There were no significant differences between the periods of treatment with placebo and with ipratropium bromide in the number of puffs subjects took daily from their $\beta_{2}$ agonist inhalers or in the diary card scores for breathlessness, cough, wheeze, or satisfactory sleep.

There were isolated reports in both treatment periods of cough, sore throat, wheeze, less sputum, rhinitis, breathlessness, and tightness in the chest. Most patients guessed which was the active treatment from its taste, and two described this as unpleasant. One man who had mild difficulty passing urine reported that this became worse after using ipratropium bromide for three and a half weeks, but did not report this after he changed to placebo.

Eight patients were withdrawn from the study. Three patients did not comply with the instructions for taking the trial medication, two had exacerbations of asthma while taking placebo, and three were with-

Table 3 Mean inspiratory flow, penetration index, and alveolar deposition of radioaerosol (as percentage of initial lung burden remaining at 24 hours) for baseline, placebo, and ipratropium bromide runs

\begin{tabular}{|c|c|c|c|c|c|c|}
\hline & \multicolumn{2}{|c|}{ Inspiratory flow $\left(l \min ^{-1}\right)$} & \multicolumn{2}{|c|}{ Penetration index } & \multicolumn{2}{|c|}{ Alveolar deposition (\%) } \\
\hline & Mean & $S E$ & Median & Range & Mean & $S E$ \\
\hline $\begin{array}{l}\text { Baseline } \\
\text { Placebo } \\
\text { Ipratropium bromide }\end{array}$ & $\begin{array}{l}43.5 \\
42.8 \\
46.9\end{array}$ & $\begin{array}{l}2.9 \\
3.1 \\
3.3\end{array}$ & $\begin{array}{l}0.28 \\
0.35 \\
0.47\end{array}$ & $\begin{array}{l}0.17-0.63 \\
0.20-0.66 \\
0.26-0.91\end{array}$ & $\begin{array}{l}20.4 \\
28.7 \\
28.7\end{array}$ & $\begin{array}{l}2.0 \\
3.4 \\
2.8\end{array}$ \\
\hline
\end{tabular}


$\%$ of initial

tracheobronchial

deposition

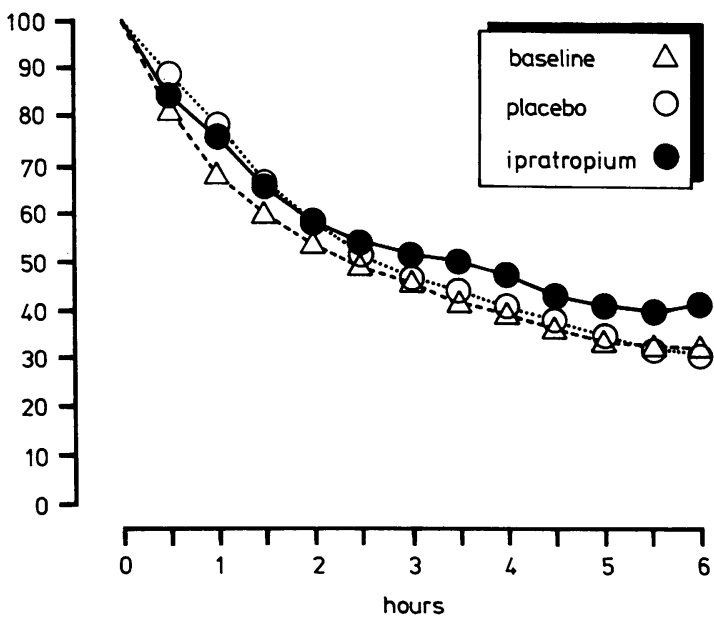

Mean tracheobronchial retention (uncorrected for sputum production) at half hourly intervals for 15 patients for baseline run and after four weeks' treatment with placebo and ipratropium bromide.

drawn while taking ipratropium bromide but for unconnected reasons.

\section{Discussion}

Ipratropium bromide is an effective bronchodilator in chronic obstructive lung disease and asthma, and its bronchodilator effect is increased and prolonged with doses up to 10 times greater than the standard dose of $40 \mu \mathrm{g} .{ }^{3-82021}$ The drug appears to be free of systemic side effects even when given in doses of up to $500 \mu \mathrm{g}$ to treat acute severe asthma. ${ }^{22}$ Indeed, it came into use as a bronchodilator because it lacked the systemic anticholinergic effects of atropine. ${ }^{23}$

Nevertheless, concern has been expressed about the use of ipratropium bromide, on the grounds that it might increase sputum viscosity and so exacerbate mucus plugging, particularly in asthma. ${ }^{24}$ The clear ance of secretions from the airways is determined by the physical characteristics of the airways, by ciliary action, and by cough. ${ }^{25}$ The clearance of lung secre tions may be impaired if any of these determinants altered.

Previous studies showed that smaller doses of iprae tropium bromide caused little or no alteration in the volume or viscoelastic properties of sputum produced by patients diagnosed as having chronic bronchitis though some probably had asthma. ${ }^{26-29}$ The results of the present study are consistent with these obsers vations, but firm conclusions about the effect of hig $\overrightarrow{\text { 而 }}$ dose ipratropium bromide on sputum cannot be drawn because the number of subjects who produce $\bar{\alpha}$ sputum was small. In studies of isolated animal airiv ways the drug showed only a mild depressant activityr on ciliary beat frequency, which was not dose re lated. ${ }^{30}$ Ipratropium bromide did not significantly reduce the frequency of spontaneous coughing in the present study, but in another study nebulised drug. reduced the cough response to inhaled citric acid itb patients with asthma, though this could have been duef to an improvement in airways impedance. ${ }^{31}$ In clinical practice, however, the overall effectiveness of lung mucus clearance is more important than each of is components, which may in any case be difficult $t \overline{8}$ evaluate. We found that ipratropium bromide inhaleg in the high dose of $200 \mu \mathrm{g}$ three times daily for fouf weeks did not alter overall tracheobronchial clear $\overrightarrow{0}$ ance. This is the most important conclusion from ou study, and it extends the observations from previou studies that ipratropium bromide does not alter lung mucociliary clearance when inhaled in single doses of up to $200 \mu \mathrm{g},{ }^{15932}$ or in regular doses of up to $40 \mu \mathrm{g}$ four times daily for a week. ${ }^{12}$ While it is difficult to assess the power of the study to detect small altez ations in mucociliary clearance, previous studies of as few as 10 or 12 subjects have demonstrated bot significant acceleration ${ }^{33}$ and retardation ${ }^{34}$ of clear ance after drug treatment; and the within subjeci coefficient of variation of the six hour tracheos bronchial clearance measurement in patients with. chronic bronchitis was $17 \% .^{35}$

Table 4 Number of coughs and wet weight and mean apparent viscosity of sputum produced during the six hour observation period, and mean 24 hour wet weight of sputum produced at the end of each four week treatment period

\begin{tabular}{|c|c|c|c|c|c|c|c|c|}
\hline & \multicolumn{6}{|c|}{ During six hour observation period } & \multirow{2}{*}{\multicolumn{2}{|c|}{$\begin{array}{l}24 \text { hour sputum wet } \\
\text { weight }(\mathrm{g})\end{array}$}} \\
\hline & \multicolumn{2}{|c|}{ No of coughs } & \multicolumn{2}{|c|}{ Sputum wet weight (g) } & \multicolumn{2}{|c|}{$\begin{array}{l}\text { Mean apparent sputum } \\
\text { viscosity }(\mathrm{mPa})\end{array}$} & & \\
\hline & Median & Range & Median & Range & Median & Range & Median & Range \\
\hline $\begin{array}{l}\text { Baseline } \\
\text { Placebo } \\
\text { Ipratropium bromide }\end{array}$ & $\begin{array}{r}28 \\
14 \\
8\end{array}$ & $\begin{array}{l}2-69 \\
1-36 \\
3-81\end{array}$ & $\begin{array}{l}4.3 \\
2.0 \\
1.9\end{array}$ & $\begin{array}{l}0.1-25.5 \\
0.5-9.2 \\
0.6-16.6\end{array}$ & $\begin{array}{l}2859 \\
2284 \\
4286\end{array}$ & $\begin{array}{r}1464-8730 \\
618-8043 \\
1011-7425\end{array}$ & $\begin{array}{r}11.6 \\
8.4 \\
11.6\end{array}$ & 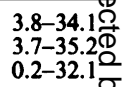 \\
\hline
\end{tabular}


There have been reports of temporary worsening of lung function after inhalation of nebulised ipratropium bromide, but this appears to be caused by bronchoconstriction rather than retention of secretions. Paradoxical impairment of lung function has occurred after administration of ipratropium bromide by wet nebulisation to patients with asthma. ${ }^{3637}$ It appears to have been caused by the hypotonicity of the solution ${ }^{38}$ then in use, and was probably due to exaggerated non-specific bronchial reactivity ${ }^{39}$ rather than retention of secretions; subjects who developed bronchoconstriction with nebulised ipratropium bromide showed bronchodilatation after inhaling the drug from a metered dose inhaler (PH Howarth, et al, personal communication). Nebulised ipratropium bromide diluted with physiological saline did not impair lung mucociliary clearance in healthy non-smokers or in patients with mild chronic obstructive bronchitis, ${ }^{40}$ even though the solution was hypotonic.

Connolly has published the only reports of bronchoconstriction developing after inhalation of ipratropium bromide from a metered dose inhaler. ${ }^{36}$ In one case wheezing increased immediately and lasted 15 minutes; it was thus unlikely to have resulted from retention of secretions. Another patient, however, experienced a progressive reduction in peak expiratory flow for four days after he started to use metered dose ipratropium bromide; progressive recovery occurred over the next two days after treatment was withdrawn. Retention of secretions might have been to blame, although this seems unlikely.

We conclude that treatment with the synthetic anticholinergic bronchodilator ipratropium bromide given in the dose of $200 \mu \mathrm{g}$ three times daily from a metered dose inhaler for four weeks is not associated with any modification of the volume or apparent viscosity of secretions, or of their clearance from the lungs.

We thank Boehringer Ingelheim Limited for financial support of this work.

\section{References}

1 Pavia D, Bateman JRM, Sheahan NF, Clarke SW. Effect of ipratropium bromide on mucociliary clearance and pulmonary function in reversible airways obstruction. Thorax 1979;34:501-7.

2 Pavia D, Bateman JRM, Sheahan NF, Clarke SW. Clearance of lung secretions in patients with chronic bronchitis: effect of terbutaline and ipratropium bromide aerosols. Eur J Respir Dis 1980;61:245-53.

3 Storms WW, Do Pico GA, Reed CE. Aerosol Sch 1000. An anticholinergic bronchodilator. Am Rev Respir Dis 1975;111:419-22.
4 Gross NJ. Sch 1000: a new anticholinergic bronchodilator. Am Rev Respir Dis 1975;112:823-8.

5 Ruffin RE, Wolff RK, Dolovich MB, Rossman CM, Fitzgerald JD, Newhouse MT. Aerosol therapy with Sch 1000. Short term mucociliary clearance in normal and bronchitic subjects and toxicology in normal subjects. Chest 1978;73:501-6.

6 Allen CJ, Campbell AH. Dose response of ipratropium bromide assessed by two methods. Thorax 1979;34: 137-9.

7 Burge PS, Harries MG, l'Anson E. Comparison of atropine with ipratropium bromide in patients with reversible airways obstruction unresponsive to salbutamol. $\mathrm{Br} J \mathrm{Dis}$ Chest 1980;74:259-62.

8 Gomm SA, Keaney NP, Hunt LP, Allen SC, Stretton TB. Dose response comparison of ipratropium bromide from a metered-dose inhaler and by jet nebulisation. Thorax 1983;38:297-301.

9 Francis RA, Thomson ML, Pavia D, Douglas RB. Ipratropium bromide: mucociliary clearance rate and airway resistance in normal subjects. $\mathrm{Br} J$ Dis Chest 1977;71:173-8.

10 Gross NJ, Skorodin MS. State of the art. Anticholinergic, antimuscarinic bronchodilators. Am Rev Respir Dis 1984;129:856-70.

11 Cotes JE. Lung function: assessment and application in medicine. 4th ed. Oxford: Blackwell Scientific Publications, 1979.

12 Knudson RJ, Slatin RC, Lebowitz MD, Burrows B. The maximal expiratory flow-volume curve. Normal standards, variability, and effects of age. Am Rev Respir Dis 1976;113:587-600.

13 Few JD, Short MD, Thomson ML. Preparation of ${ }^{99 m} \mathrm{Tc}$ labelled particles for aerosol studies. Radiochem Radioanal Lett 1970;5:275-7.

14 Camner P, Philipson K. Human alveolar deposition of $4 \mu \mathrm{m}$ teflon particles. Arch Environ Health 1978;36:181-5.

15 Fazio F, Lafortuna C. Effect of inhaled salbutamol on mucociliary clearance in patients with chronic bronchitis. Chest $1981 ; 80$, suppl:827-30.

16 Agnew JE, Bateman JRM, Pavia D, Clarke SW. Radionuclide demonstration of ventilatory abnormalities in mild asthma. Clin Sci 1984;66:525-31.

17 Newman SP, Pavia D, Clarke SW. How should a pressurized beta-adrenergic bronchodilator be inhaled? Eur $J$ Respir Dis 1981;62:3-21.

18 Pavia D, Sutton PP, Lopez-Vidriero MT, Agnew JE, Clarke SW. Drug effects on mucociliary function. Eur $J$ Respir Dis 1983;64, suppl 128:304-17.

19 Siegel S. Nonparametric statistics for the behavioral sciences. Tokyo: McGraw-Hill Kogakusha, 1956.

20 Poppius H, Salorinne Y. Comparative trial of a new anticholinergic bronchodilator, Sch 1000 , and salbutamol in chronic bronchitis. Br Med J 1973;iv:134-6.

21 Petrie GR, Palmer KNV. Comparison of aerosol ipratropium bromide and salbutamol in chronic bronchitis and asthma. $\mathrm{Br}$ Med J 1975;i:430-2.

22 Ward MJ, Fentem PH, Smith WHR, Davies D. Ipratropium bromide in acute asthma. $\mathrm{Br} \mathrm{Med} J$ 1981;282:598-600.

23 Engelhardt A, Klupp HH. The pharmacology and toxicology of a new tropane alkaloid derivative. Postgrad Med J 1975;51, suppl 7:82-4.

24 Crompton GK. Sputum viscosity and long-term ipratropium bromide nebuliser therapy. Lancet 1982; i: 1243. 
25 Newhouse M, Sanchis J, Bienenstock J. Lung defense mechanisms [first of two parts]. $N$ Engl J Med 1976;295:990-8.

26 Ghafouri MA, Patil KD, Kass I. Sputum changes associated with the use of ipratropium bromide. Chest 1984;86:387-93.

27 Krieger E, Reitberger U. Sputum rheology following treatment with Sch $1000 \mathrm{MDI}$ and orciprenaline MDI. Postgrad Med J 1975;51, suppl 7:108.

28 Puchelle E, Uffholtz H. Sputum viscoelasticity following administration of Sch 1000 MDI. Postgrad Med J 1975;51, suppl 7:109.

29 Streseman E. Total airways resistance $\left(R_{1}\right)$, sputum volume and rheology in patients with chronic bronchitis following treatment with Sch $1000 \mathrm{MDI}$ and placebo. Postgrad Med J 1975;51, suppl 7:110.

30 Iravani J, Melville GN. Ciliary movement following various concentrations of different anticholinergic and adrenergic bronchodilator solutions in animals. Postgrad Med J 1975;51, suppl 7:108.

31 Pounsford JC, Saunders KB, Davidson RN. Effect of bronchodilators on the cough response to citric acid in normal subjects and asthmatics. Thorax 1984;39:712.

32 Foster WM, Langenback EG, Glaser ML, Bergofsky EH. Acute effect of ipratropium bromide at therapeutic dose on mucus transport of adult asthmatics. Eur $J$
Respir Dis 1983;64, suppl 128:554-7.

33 Sutton PP, Pavia D, Bateman JRM, Clarke SW. The effect of oral aminophylline on lung mucociliary clear $\overline{\bar{\omega}}$ ance in man. Chest 1981;80, suppl:889-91.

34 Pavia D, Thomson ML. Inhibition of mucociliary clear ance from the human lung by hyoscine. Lance? 1971;i:449-50.

35 Pavia D, Sutton PP, Agnew JE, Lopez-Vidriero MT Newman SP, Clarke SW. Measurement of bronchial mu cociliary clearance. Eur J Respir Dis 1983;64, supp? 127:41-56.

36 Connolly $\mathrm{CK}$. Adverse reaction to ipratropium bromide Br Med J 1982;285:934-5.

37 Patel KR, Tullett WM. Bronchoconstriction in response to ipratropium bromide. $\mathrm{Br}$ Med $J$ 1983;286:1318.

38 Mann JS, Howarth PH, Holgate ST. Bronchoconstriction induced by ipratropium bromide in asthma: relation to hypotonicity. $\mathrm{Br} \mathrm{Med} J$ 1984;289:469;

39 Schoeffel RE, Anderson SD, Altounyan RE. Bronchia hyper-reactivity in response to inhalation of ultraer sonically nebulised solutions of distilled water and saline은 Br Med J 1981;283:1285-7.

40 Matthys $H$, Muller $M$, Konietzko $N$, Adam WE Tracheo-bronchial clearance studies with and withoup Sch 1000 using ${ }^{99 \mathrm{~m}}$ technetium sulphate $\left({ }^{99 \mathrm{~m}} \mathrm{Tc}\right)$ particles Postgrad Med J 1975;51, suppl 7:108. 